\title{
Prevalence of Tooth Loss in A Community in The South-West of Nigeria
}

\author{
Oremosu $\mathrm{OA}^{1}$, Uti $\mathbf{O G}^{2}$
}

\begin{abstract}
Aim: The aim of this study was to determine the pattern and prevalence of tooth loss amongst community dwelling adults in a suburban area of Lagos.

Methods: A questionnaire based study was carried out in a community in Lagos, Nigeria. Causes, pattern and factors affecting tooth loss were elucidated.

Result: Prevalence of adults with at least one missing tooth was 33.6\%. More than half (64.1\%) of the respondents had lost their teeth for more than 5 years. Tooth loss $(42.3 \%)$ was more in the lower posterior region. There was a significant association of tooth loss to increasing age, previous visit to the dentist and gender. The males had $38.7 \%$ tooth loss in the anterior region while females had more tooth loss in the posterior region.
\end{abstract}

Conclusion: Prevalence of tooth loss was high. Tooth loss was more in the males. A higher percentage of tooth loss was found amongst the elderly.

Keywords: Prevalence, Tooth loss, Pattern, Community dwelling adults

\section{Lecturer \\ Department of Restorative Dentistry \\ Faculty of Dental Sciences, University of Lagos \\ ${ }^{2}$ Senior Lecturer \\ Department of Preventive Dentistry \\ Faculty of Dental Sciences, University of Lagos}

\section{Contact Author}

Dr OA Oremosu

teeoremz2000@yahoo.com omolaraza@yahoo.com

J Oral Health Comm Dent 2014;8(3)154-159

\section{INTRODUCTION}

Tooth loss is recognized as a public health problem and used as an important measure of the oral health of a population $(1,2)$. It is an important measure for assessing the standard, availability and utilization of both curative and preventive dental care in a given population (3). The etiology of tooth loss is complex, it includes factors such as existing diseases, hygiene habits and use of dental clinics (1). The major causes of tooth loss are periodontal disease and dental caries. Periodontal disease is more prevalent in the older age group while caries is associated with the younger age group $(4,5)$. Other causes of tooth loss are trauma and orthodontic treatment. Tooth loss is associated with esthetic, functional, psychological and social impacts. The impacts of tooth loss include decreased functions of speech and mastication especially in the elderly $(6,7)$. It may affect their nutritional choices, their oral and ultimately systemic health and thereby diminish the quality of life (8). It also decreases self esteem and psychological status of individuals $(9,10)$.

A review of tooth loss in Europe (11), showed a decline in prevalence over the years with the prevalence of tooth loss falling from $79 \%$ to $57 \%$ in United kingdom amongst the 65-74year old adults between 1968-1988, in Sweden it dropped from 19\% in 1975 to $3 \%$ in 1997, while Germany with a prevalence of $24 \%$ in 1998 dropped to $22 \%$ in 2006. In Switzerland, prevalence of edentulism dropped from $1.1 \%$ in 1993 to $0.4 \%$ in 2002 amongst the 35 44 years. In the USA, the prevalence of edentulism was $10.8 \%$ in 1999 it decreased to $7.7 \%$ in 2002 . This reduction has been largely because efforts have been directed to preventing the most common causes of tooth loss (12). 
Some studies have shown tooth loss prevalence in developing countries to be high. In Sri Lanka (13), the overall prevalence of tooth loss in 2011 was $81.6 \%$, while a study amongst adults in Sudan (14), having a minimum of one missing teeth reported a prevalence of $78 \%$ tooth loss. In these studies, prevalence of edentulism increased with age.

Most studies done in Nigeria have reported that caries and periodontal reasons are still the major causes of tooth loss (15-18). Adeyemo et al in 2004 reported that tooth loss due to caries and periodontal reasons had increased when compared to a study done 16 years earlier in a similar location, it also highlighted other indications for extraction and subsequent tooth loss like orthodontic and impaction extraction. A prevalence of $12.3 \%$ tooth loss has also been reported by Ogini with a significant female preponderance (15).

Socioeconomic factors affect the treatment seeking attitude of patients (19), and this may influence the individuals who tolerate edentulous spaces without seeking for professional attention. While other sociodemographic factors have been associated with tooth loss (20), treatment seeking attitude may be an indication of success or failure in dentistry and dental health programmes. Success may be measured by a declining rate of edentulism and increased number of retained teeth (20).

There is a need to study prevalence of tooth loss, as a decline may be an indication of increased availability and accessibility to oral diseases prevention and control programs (2).

While a number of studies have been published on prevalence of tooth loss in Nigeria, none to our knowledge has been reported on community dwelling adults. Therefore the aim of this study was to determine the pattern and prevalence of tooth loss amongst community dwelling adults in a suburban area of Lagos.

\section{MATERIALS AND METHODS}

A cross sectional descriptive study was conducted among community dwelling adults in idiaraba, a suburb of Mushin local government area in Lagos state. The questionnaire was pretested in a similar community and adjusted accordingly.

Four streets were selected by simple random sampling from a list of streets. All adults in each household on the streets were included in study.

An interviewer administered questionnaire was used to collect data. This was done after an explanation of the study methods and verbal consent was obtained from all consenting adults living in each household aged 15 years and above.

The questionnaire included the respondents' socio-demographic background which included their age, gender, religion, educational level and

\begin{tabular}{|c|c|c|}
\hline & $\mathbf{N}$ & $\%$ \\
\hline \multicolumn{3}{|l|}{ AGE RANGE } \\
\hline $26-40$ & 161 & 38.1 \\
\hline $41-65$ & 114 & 27.0 \\
\hline$>65$ & 15 & 3.5 \\
\hline \multicolumn{3}{|l|}{ GENDER } \\
\hline Female & 211 & 49.9 \\
\hline Male & 212 & 50.1 \\
\hline $\begin{array}{c}\text { EDUCATIONAL } \\
\text { None }\end{array}$ & EDUCATIONAL LEVEL & 23.4 \\
\hline Primary & 88 & 20.8 \\
\hline Secondary & 181 & 42.8 \\
\hline Tertiary & 55 & 13.0 \\
\hline \multicolumn{2}{|l|}{ ETHNICITY } & 10.6 \\
\hline Yoruba & 110 & 26 \\
\hline Hausa & 224 & 53 \\
\hline Others & 44 & 10.4 \\
\hline \multicolumn{3}{|l|}{ RELIGION } \\
\hline Muslims & 309 & 73.0 \\
\hline
\end{tabular}

income, after which clinical examination was done for tooth loss by using visual and tactile examination. The study participants were examined using spatula and sterile mirror with respondent sitting upright under a good source of light. Missing teeth were classified as anterior and posterior so that a distinction could be made between esthetic and functional needs.

\section{Analysis}

The collected data was analyzed using the EPI info version 7 statistical soft ware. The chi square test of association was used where appropriate. Difference was taken as significant at the level of $\mathrm{P}<0.05$

\section{RESULTS}

There were 423 respondents, comprising 211(49.9\%) females and 212(50.1\%) males, giving an equal female to male and median age 31 years. Most of the respondents $181(42.8 \%)$ had secondary ratio. The age range was 15 - 95years 


\section{Table 2: Factors affecting prevalence of tooth loss}

\begin{tabular}{|c|c|c|}
\hline & Percentage (\%) & $P$ value \\
\hline \multicolumn{3}{|l|}{ Age } \\
\hline $15-25$ & 23.3 & \\
\hline $26-40$ & 27.3 & $0.000^{*}$ \\
\hline $41-65$ & 49.1 & \\
\hline$>65$ & 73.3 & \\
\hline \multicolumn{3}{|l|}{ Gender } \\
\hline Female & 28.4 & \\
\hline Male & 38.7 & $0.033^{*}$ \\
\hline \multicolumn{3}{|c|}{ Perception of oral health } \\
\hline Good & 27.9 & \\
\hline \multicolumn{3}{|l|}{ Fair 37.7} \\
\hline \multicolumn{3}{|l|}{ Poor 54.2} \\
\hline \multicolumn{3}{|l|}{$0.010^{*}$} \\
\hline \multicolumn{3}{|c|}{ Previous visit to the dentist } \\
\hline \multicolumn{3}{|l|}{ Visit 81.4} \\
\hline No visit & 18.3 & $0.000^{*}$ \\
\hline \multicolumn{3}{|c|}{ Visit in the last one year } \\
\hline Yes & 70.6 & \\
\hline No & 34.3 & $0.005^{*}$ \\
\hline \multicolumn{3}{|c|}{ Educational level } \\
\hline None & 38.4 & \\
\hline Primary & 36.4 & \\
\hline Secondary & 29.3 & \\
\hline Tertiary & 34.5 & 0.414 \\
\hline \multicolumn{3}{|c|}{ Income per day(Naira) } \\
\hline $50-1000$ & 36.3 & \\
\hline $1001-2000$ & 31.7 & \\
\hline 2001-5000 & 27.5 & \\
\hline $5001-20,000$ & 30.0 & 0.722 \\
\hline
\end{tabular}

education, 99(23.4\%) had no formal education, while an even smaller number $55(13 \%)$ had tertiary education. A large number $224(59 \%)$ of the respondents were hausas from the northern part of Nigeria though this study was carried out in the South Western part of the country (table 1).

The daily income of respondents ranged from N50 (\$0.31) to N20,000 (\$125) with a median value of $\mathrm{N} 1000(\$ 6.25)$

\section{Tooth Loss}

In this study tooth loss prevalence was high as $33.6 \%$ of the subjects had lost one or more teeth, and the mean tooth loss was $2.4 \pm 3.0$ (table 3). More than half $(64.1 \%)$ of the respondents had lost their teeth for more than 5 years. Prevalence of tooth loss was significant-
Table 3: Pattern of Tooth loss

Pattern of Tooth loss

$\%$

\begin{tabular}{ll}
\hline $\begin{array}{l}\text { Respondents } \\
\text { Missing teeth }\end{array}$ & $142(33.6)$ \\
\hline No missing teeth & $281(66.4)$ \\
\hline $\begin{array}{l}\text { No of Missing teeth } \\
1-3\end{array}$ & $118(83.1)$ \\
\hline $4-6$ & $19(13.4)$ \\
\hline$>6$ & $5(3.5)$ \\
\hline $\begin{array}{l}\text { Duration } \\
<12 \text { months tooth loss }\end{array}$ & $23(16.2)$ \\
\hline $1-4$ years tooth loss & $28(19.7)$ \\
\hline$>5 y e a r s$ tooth loss & $91(64.1)$ \\
\hline $\begin{array}{l}\text { Location } \\
\text { Upper anterior }\end{array}$ & $33(23.2)$ \\
\hline Upper posterior & $38(26.8)$ \\
\hline Lower Anterior & $11(7.7)$ \\
\hline Lower posterior & $60(42.3)$ \\
\hline Mean tooth loss was $2.4 \pm 3.0$ S.D \\
\hline
\end{tabular}

ly associated with gender $(P=0.033)$, increasing age $(\mathrm{P}=0.000)$, poor perception of oral health $(\mathrm{P}=0.010)$ and previous visit to the dentist $(0.000)$, but not significantly associated with level of education $(\mathrm{P}=0.414)$ or income $(\mathrm{P}=0.722)$

\section{Pattern}

Majority of the teeth (42.3\%) were lost in the lower posterior segments of the mouth. A significantly higher proportion of females had lost teeth in the lower posterior segments compared to men who had lost more anterior teeth $(P=0.011)$. Factors that influence the pattern as shown in fig 2

Forty five $(31.7 \%)$ of the lost teeth were extracted by the dentist while $3.5 \%(\mathrm{n}=5)$ had been extracted by local traditional doctors.

\section{Causes of tooth loss}

More than a quarter of the respondents claimed the teeth were lost as a result of periodontal disease $(26.8 \%)$ referred to as shaking teeth and carious lesion(20.4\%) referred to as holes. While traumatic causes of tooth loss $(17.6 \%)$ included road traffic accidents, 

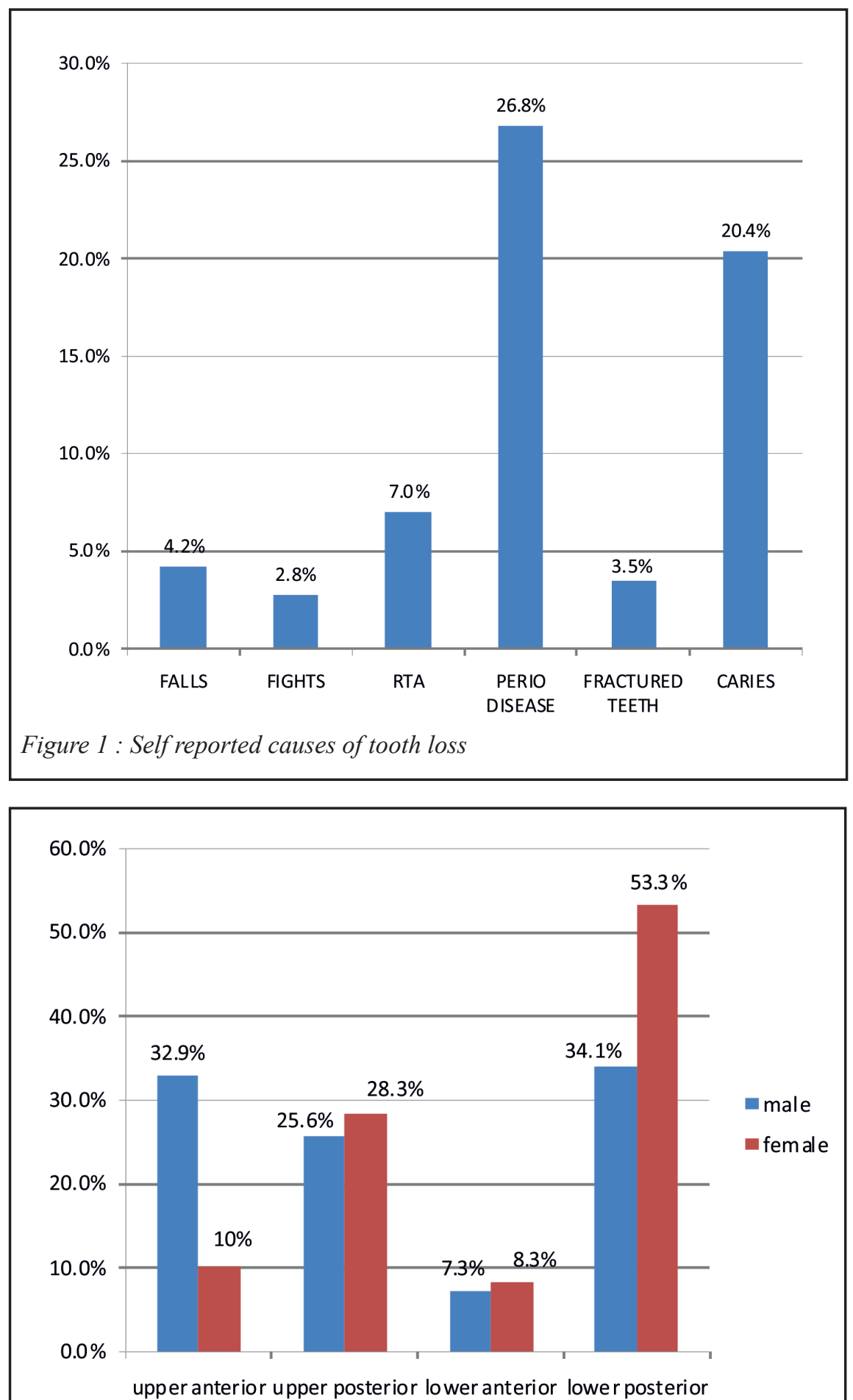

Figure 2: Pattern of tooth loss by gender

falls and fights.

\section{Perception of oral health}

More than half (54.2\%) of the respondent perceived their oral health to be poor (table 2)
5,15-17). tooth loss has been shown to substantially affect chewing, aesthetics and quality of life (6-8). Studies have shown factors related to tooth loss, however these studies where hospital based (15-19), and would report on prevalence on presenting patients, and may not give the true picture of prevalence of tooth loss in the community. This study revealed a high prevalence of tooth loss amongst community dwelling adults. However, the data must be interpreted with caution because while the study was conducted in a community, the sample is not ethnically representative of Nigeria. The study was in the South Western region of Nigeria but $53 \%$ of the population studied was ethnically from the North. In this study, prevalence of tooth loss is $33.6 \%$ which is higher than a reported prevalence of $12.3 \%$ in a suburban population (13), but lower than reported in studies from Chennai India with a prevalence of $45.5 \%$.

Though an equal ratio of male and female subjects were seen, in this study the male subjects had a significantly higher prevalence of tooth loss than the females. This finding is at variance to an earlier report from Ile Ife Nigeria, in which the prevalence of tooth loss was higher in women than men (15). This could have been due to the difference in the populations studied. While our study was in community dwelling adults, the earlier study was in patients attending oral surgery clinics in Teaching hospitals and general hospitals.

While higher male prevalence has also been reported by some studies,(21-22) other studies have concluded that gender is not a significant predictor of tooth loss (23-24). This is contrary to most other studies where there is a female preponderance of tooth loss $(2,11,20,25)$, these studies speculated that the female gender may be more sensitive to their dental needs and therefore tend to seek intervention services and experience greater tooth loss (20). 
The two major causes of tooth loss in this study were periodontal disease and dental caries. A previous study in Nigeria by Adeyemo et al (16), on indications for tooth extraction reported that Caries and its sequelae and periodontal diseases were the main reasons for tooth extraction which is in consonance with this current study. Another study (15), also reported this trend that Dental caries $(56.4 \%)$ was the leading cause of tooth loss followed by periodontal disease (24.6\%).

Though the major causes of tooth loss have been periodontal disease and dental caries, other factors like traumatic injuries and surgical extractions have been associated with tooth loss. In this study traumatic loss of teeth due to falls, fights and road traffic accidents was significantly associated with the male gender. All the respondents who had lost their teeth as a result of road traffic accident were males. The advent of use of Motor cycles as a means of public transportation in Nigeria has possibly led to an increase in trauma to anterior teeth.

Age is a predisposing sociodemographic factor associated with tooth loss, in this study an increase in age was associated with tooth loss. This result is in agreement with previous studies where tooth loss increased as the age of the respondents increased $(2,7,11,21,22)$. The highest number and percentage of tooth loss $73.3 \%$ was found amongst the older age group of 65 years and above.

Most lost teeth were in the posterior region which is similar to most studies done $(12,13,15,21)$.

A visit to the dentist is positively associated to tooth loss. A significant number of males $82(57.7 \%)$ who had experienced tooth loss had also been to the dentist. An increased risk in tooth loss has been associated with ability to asses to the dental care and therefore, individuals with less risk of assessing or entering the dental care system have a lower risk of tooth loss. It has been proposed that Oral problems and dental symptoms would have a direct effect on the use of dental services and an indirect effect on tooth loss $(23,26)$. This may be due to problem based attendance of the clinic, with the patients presenting late and inability to save the tooth and subsequent tooth loss.

The perception of oral health was positively associated with tooth loss as more people who had lost teeth perceived their oral health to be poor. This is in agreement with a study that associated retention of teeth with positive self perceived oral health (27).

In this study, level of education had no significant association with tooth loss. This is contrary to studies which found an increased risk of tooth loss with low levels of education $(2,21,22)$.

\section{CONCLUSION}

The prevalence of tooth loss was high among this community dwelling adults with the major causes of tooth loss being periodontal disease and dental caries. The males had a higher prevalence of tooth loss than the females, this is because they visited the dentist more than the females and also experienced significant traumatic injuries to the anterior teeth, while the females had more tooth loss in the posterior region. Tooth loss was found to increase with age with a higher percentage amongst the elderly aged 65 and above.

The results of this study show that tooth loss is common in this community, and these causes are preventable, there is therefore a need for enlightenment through dental education to reduce this trend.

\section{REFERENCES}

1. Petersen PE. The world oral health report 2003: continuous improvement of oral health in the 21st century - the approach of the WHO Global Oral Health Programme. Community Dent Oral Epidemiol 2003;31(1):3-24.

2. Susin C, Oppermann RV, Haugejorden O, Albandar JM. Tooth loss and associated risk indicators in an adult urban population from south Brazil. Acta Odontol Scand 2005;63:85-93.

3. Agagnon-Varelzides A, Komboli M, Tsami A, Mitsis F. Pattern of tooth loss in a selected population in Greece. Community Dent Oral Epidemiol 1986;14:349-52.

4. Baelum V, Fejerskov O. Tooth loss as related to dental caries and periodontal breakdown in adult Tanzanians. Community Dent Oral Epidemiol 2006;14(6):353-357.

5. Bagramian RA, Garcia Godoy F, Volpe AR: The global increase in dental caries. A pending public health crisis. Am J Dent 2009;22(1):3-8.

6. Mishellany-Dutour A, Renaud J, Peyron MA, Rimek F, Woda A. Is the goal of mastication reached in young dentates, aged dentates, and aged denture wearers? Br J Nutr 2008;99:121-28.

7. Musacchio E, Perissinotto E, Binotto P, Sartori L, Silva-Netto F, Zambon S, et al. Tooth loss in the elderly and its association with nutritional status, socioeconomic and lifestyle factors. Acta Odontol Scand 2007;65:78-86.

8. Akpata E, Otoh E, Enwonwu C, Adeleke O, Joshipura K. Tooth loss, chewing habits, and food choices among older Nigerians in Plateau State: a preliminary study. Community Dent Oral Epidemiol 2011;39(5):409-15.

9. Slade GD, Nuttall N, Sanders AE, Steele JG, Allen PF, Lahti S. Impacts of oral disorders in the United Kingdom and Australia. Br Dent J 2005;198:489-93.

10. Omar R, Tashkandi E, Abduljabbar T, Abdullah MA, Akeel RF. Sentiments expressed in relation to tooth loss: a quali tative study among edentulous. Saudis Int J Prosthodont 2003;16:515-20

11. Müller $F$, Naharro M, Carlsson GE. What are the prevalence and incidence of tooth loss in the adult and elderly population in Europe? Clin Oral Implants Res 2007; 18(3):2-14.

12. Renson CE, Crielaers PJA, Ibikunle SA, Pinto VG, Ross CB, Infirri JS. Changing patterns of oral health and implications for oral health manpower. Part I. Report of a working group convened jointly by the Federation Dentaire Internationale and the WHO. Int Dent J 1985;35:235-51.

13. Perera R, Ekanayake L. Tooth loss in Sri Lankan adults. Int Dent J 2011;61:7-11.

14. Khalifa N, Allen PF, Abu-bakr NH, AbdelRahman ME. Factors associated with tooth loss and prosthodontic status among Sudanese adults. J Oral Sci 2012;54(4):303-12.

15. Oginni FO. Tooth loss in a sub-urban Nigerian population: causes and pattern of mortality revisited. Int Dent J 2005;55:1723.

16. Adeyemo WL, Oderinu HO, Oluseye SB, Taiwo OA, Akinwande JA. Indications for extraction of permanent teeth in a 
Nigerian teaching hospital: a 16-year follow-up study. Nig Q J Hosp Med 2008;18(3):128-32.

17. Odusanya SA. Tooth loss among Nigerians: causes and pattern of mortality. Int J Oral maxillofac Surg 1987;16:18489.

18. Esan TA, Olusile AO, Ojo MA, Udoye $\mathrm{Cl}$, Oziegbe EO, Olasoji HO. Tooth loss amongst Nigerians treated in teaching Hospitals: a national pilot study. $J$ Contemp Dent Pract 2010;14;11(5):17-24

19. Esan TA, Olusile AO, Akeredolu PA, Esan AO. Socio-demographic factors and edentulism: the Nigerian experience. BMC Oral Health 2004;4:3.

20. Hugo FN, Hilgert JB, De Sousa Mda L, da Silva DD, Pucca GA. Correlates of partial tooth loss and edentulism in the Brazilian elderly. Community Dent Oral Epidemiol 2005;35:224-32

21. George B, John J, Saravanan S, Arumugham IM. Prevalence of permanent tooth loss among children and adults in a suburban area of Chennai. Indian J Dent Res 2011;22:364.

22. Hamasha AA, Sasa I, Qudah MA. Risk indicators associated with tooth loss in Jordanian adults. Community Dent Oral Epidemiol 2000;28:67-72.

23. Kim H, Lee S, Cho S, Patton LL, Ku Y. Associations between missing teeth with unmet needs and socioeconomic status among south Korean dentate government employees. J Publ Health Dent 2007;67: 174-78.

24. Kaimenyi JT, Ndung'u FI, Maina SW, Chindia ML. Oral hygiene habits and dental health awareness of Kenyan children aged 9-15 years in a periurban and urban school. East Afr Med $J$ 1993;70:67-70.

25. Haugejorden O, Klock KS, Trovik TA. Incidence and predictors of self-reported tooth loss in a representative sample of Norwegian adults. Community Dent Oral Epidemiol 2003;31:261-68.

26. Moreia R, Nico LS, Barrozo LV, Pereira JR. Tooth loss in Brazilian middle-aged adults: multilevel effects. Acta Odontol Scand 2010;68:269-77

27. Matthias RE, Atchison KA, Lubben JE, De Jong F, Schweitzer SO. Factors affecting self-ratings of oral health. $J$ Public Health Dent 1995;55(4):197-204. 